DOI: https://dx.doi.org/10.18203/2320-1770.ijrcog20211543

Case Report

\title{
Scar endometriosis: a mystery entity
}

\section{Jyoti Kankanala*}

Department of Obstetrics and Gynecology, Continental Hospital, Telangana, Hyderabad, India

Received: 08 February 2021

Revised: 14 March 2021

Accepted: 15 March 2021

\author{
*Correspondence: \\ Dr. Jyoti Kankanala, \\ E-mail: jyoti.kankanala@gmail.com
}

Copyright: (C) the author(s), publisher and licensee Medip Academy. This is an open-access article distributed under the terms of the Creative Commons Attribution Non-Commercial License, which permits unrestricted non-commercial use, distribution, and reproduction in any medium, provided the original work is properly cited.

\begin{abstract}
Scar Endometriosis is described as having an active endometrial tissue at the scar area outside the uterine cavity. Corner stone for diagnosis is proper history, clinical examination and suspicion-based imaging. Caesarean scar endometriosis (CSE) usually seen following procedures like caesarean sections, hysterectomies. Time of presentation can be very variable so yet times difficult to suspect. Once suspected Convincing patient that they have active glands other than in uterine cavity is not easy. Hence proper imaging and biopsy is needed to backup for thorough counselling and treatment to improve the quality of life.
\end{abstract}

Keywords: Endometriosis; Ectopic endometriosis, Scar endometriosis, Painful scar

\section{INTRODUCTION}

Endometriosis is abnormal placement of active endometrium glands outside uterine cavity. ${ }^{1}$ Its incidence in India difficult to ascertain as we don't have a central register for the same However $10 \%$ to $15 \%$ of women might be getting affected all over the globe. This can be the cause for painful periods (dysmenorrhoea), painful intercourse (dyspareunia), painful defecation and painful urination (dysuria) and other varied symptoms which are rare in some cases. ${ }^{2,3}$

A rare case notified of involvement of the rectus abdominis muscle in a virgin abdomen. ${ }^{4}$ One theory of retrograde menstruation, where in the endometrial migration occurs through fallopian tubes to pelvic cavity. This theory along with possible haematogenous or lymphatic circulation can be assumed as cause of deposits. Strangely if these theories are to be assumed but incidence of endometriosis is very less as so many women have menstrual cycles. So there, might be unexplained reasons or other immunologic, hormonal or inflammatory. ${ }^{6}$ factors. Müllerian remnants which weren't differentiated and migrated can also lead to endometriosis. ${ }^{6}$ However, in most cases due to fear of surgery or anaesthesia or financial constraints many suffer and don't go for invasive diagnosis via laparoscopy. So, it a vicious cycle of delay diagnosis and reduced quality of life.

\section{CASE REPORT}

A 36 year young P2L2 with a BMI of 28 with two previous caesarean sections (CS), last CS was 5 years ago. She presented to the OPD with complaints of painful lump at the corner of scar especially during periods and post periods with pelvic symptoms like heavy periods, since 3 years. She doesn't have any other significant history. On examination, abdomen soft but there was a firm tender 5 $\mathrm{cm}$ nodule not mobile felt at the corner of the scar without other signs of inflammation. Patient was sent for Ultrasonography with the suspicion of scar endometriosis.

Ultrasonography reports presented an irregular hypoechoic lesion approximately measuring $3.0 \times 2.7 \mathrm{~cm}$ in left iliac fossa region at the lateral margin of previous caesarean section scar predominantly in deep subcutaneous plane, extending to involve left rectus abdominis muscle. Another small hypo echoic lesion measuring $1.1 \times 0.6 \mathrm{~cm}$ in left rectus abdominis muscle cranial to the larger lesion and similar lesion also and right rectus abdominis muscle. Urinary bladder was normal in contour, capacity and wall thickness. Discussed with 
radiology plan and there was no need for MRI. After detail discussion we planned for laparoscopy (to rule pelvic deposits) dilatation curettage and Mirena coil insertion after surgical excision of endometriosis on scar and Mesh repair, same was performed under General Anaesthesia and later TA (transverse abdominis plane) block given. Patient stood procedure well.

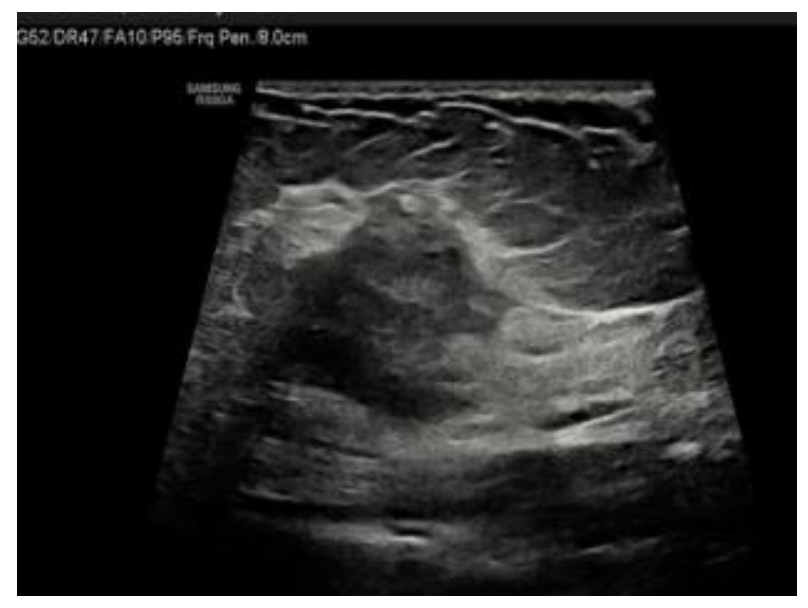

Figure 1: USG endometriosis.

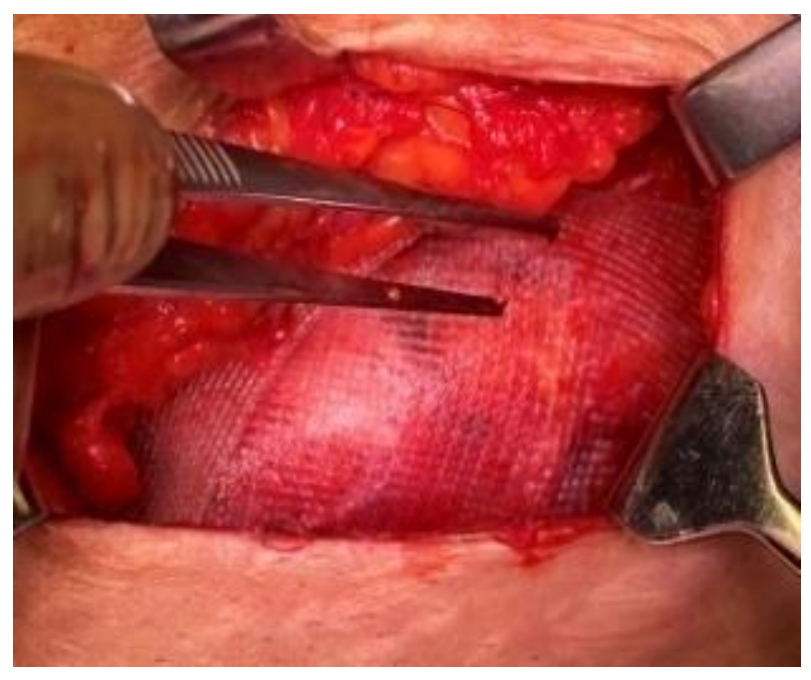

Figure 2: Scar mesh repair.

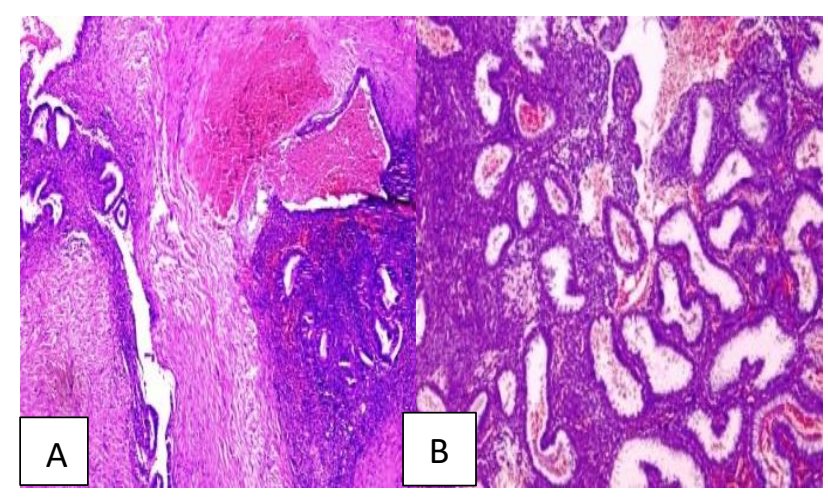

Figure 3 (A and B): Histopathology of endometriosis.

\section{DISCUSSION}

In recent study, 198 cases of CSE over a period of 13 years, providing detailed information that helps us to better understand the clinical characteristics of this rare condition. ${ }^{7}$ Most of the endometriomas were located in a corner of the incision scar: $83.0 \%$ in Pfannenstiel incision scars and $84.2 \%$ in vertical midline incision scars. This is probably because endometrial cells are less easily removed from the corners of the incisions during the procedure.

The second cause is a larger nutrient supply; angiogenesis plays an important role in the pathogenesis of endometriosis. Therefore, more blood loss in the Pfannenstiel incision would provide a relatively rich nutritional environment for the implantation and growth of residual endometrial cells, favouring the occurrence of scar endometriosis. Consistent with this explanation, all 11 patients in this study who had multiple endometriomas had Pfannenstiel incisions.

Interesting result from this study is that deeper endometrioma locations are correlated with longer latency periods. This is probably due to the fact that the deeper endometriomas could not be easily noticed. ${ }^{8}$

SE can undergo malignant change, which is rapidly fatal and has a survival rate of only $57 \%$. Hence, it is necessary to take precautions to prevent or reduce the occurrence of SE.

On the basis of the implantation theory, we propose a variety of measures: careful flushing and irrigating before closure; using separate needles for uterine and abdominal closure; and not using a sponge to clean the endometrial cavity following complete delivery. Extending the breastfeeding period to delay menstruation has also been proposed for preventing careful flushing and irrigation of the adipose layer and fascia layer during closure is critical. $^{9}$

Surgical treatment should be considered as the best treatment wherever feasible and medical treatment as add on if needed with lesser time and dose and cater individual needs explaining all benefits and risk. ${ }^{10}$ Thumb rule should be talking in the way they understand better and follow up.

\section{CONCLUSION}

If patient comes with complaints of pain over or nearing scar and a history of previous caesarean or hysterectomy try to evaluate and keep under observation and don't hesitate to get any imaging modalities to reconfirm so as to prevent further damage and to improve quality of life for her and indirectly their family.

\section{ACKNOWLEDGMENTS}

Authors would like to thank anaesthetist Dr Sumanth Kankanala for his support during study. 
Funding: No funding sources

Conflict of interest: None declared

Ethical approval: Not required

\section{REFERENCES}

1. Zhang P, Sun Y, Zhang C, Yang Y, Zyang L, Wang $\mathrm{N}$, et al. Caesarean scar endometriosis: presentation of 198 cases and literature review. BMC Women's Health. 2019;19:14.

2. American College of Obstetricians and Gynaecologists. Practice bulletin no. 114management of endometriosis. Obstetrics and Gynaecology. 2010;116(1)223-6.

3. Bektaş H, Bilsel Y, Sar YS, Feyzhulla E, Oguz K, Deniz M, et al. Abdominal wall endometrioma; a 10year experience and brief review of the literature, $\mathrm{J}$ of Surg Res. 2010;164(1):77-81.

4. Mistrangelo M, Gilbo N, Cassoni P, Micalef S, Faletti R, Miglietta C, et al. Surgical scar endometriosis. Surg Today. 2014;44(4):767-72.

5. Paşalega M, Mirea C, Vîlcea ID, Vasile IE, Pleşea FC, Meşină $\mathrm{C}$ et al. Parietal abdominal endometriosis following cesarean section. Rom $\mathrm{J}$ of Morphol and Embryol, 2011;52(1):503-8.
6. Marquez JC, Márquez J, Arratzoa JA, Pérez G, Espinoza A. Endometriosis extrapelviana de ubicación perineal. Rev Chil Obste Ginecol. 1995;60(1):1-4.

7. Leite GKC, De Carvalho LFP, Korkes H, Guazzelli TF, Kenj G, Viana ADT. Scar endometrioma following obstetric surgical incisions: retrospective study on 33 cases and review of the literature. Sao Paulo Med J. 2009;127(5):270-7.

8. Horton JD, DeZee KJ, Ahnfeldt EP, Wagner M. Abdominal wall endometriosis: a surgeon's perspective and review of 445 cases. Am J of Surg. 2008;196(2):207-12.

9. Emre A, Akbulut S, Yilmaz M, Bozdag Z. Laparoscopic trocar port site endometriosis: a case report and brief literature review, Int Surg, 2012;97(2):135-9.

10. Ideyi SC, Schein M, Niazi $M$ and Gerst PH. Spontaneous endometriosis of the abdominal wall. Dig Surg. 2003;20(3):246-8

Cite this article as: Kankanala J. Scar endometriosis: a mystery entity. Int J Reprod Contracept Obstet Gynecol 2021;10:2075-7. 